\title{
A EXPERIÊNCIA DE GESTÃO DE UMA MINI EMPRESA COMO MÉTODO PARA EDUCAÇÃO EMPREENDEDORA
}

Antonia Mônica Cavalcante Sôto ${ }^{1}$ Socorro Braun ${ }^{1}$

${ }^{1}$ Instituto Federal de Educação, Ciência e Tecnologia do Ceará 


\section{A EXPERIÊNCIA DE GESTÃO DE UMA MINI EMPRESA COMO MÉTODO PARA EDUCAÇÃO EMPREENDEDORA}

\section{Resumo}

A criação e gerenciamento de uma miniempresa no ambiente acadêmico como método de ensino, fornece ao educando: conhecimento, inspiração, orientação, encorajamento e motivação para empreender. Além de promover aprendizado empreendedor e a troca de experiências. Nessa perspectiva, o objetivo deste estudo foi demonstrar a prática de criação e gerenciamento de uma miniempresa, como metodologia de ensino e suas contribuições para o desenvolvimento de características empreendedoras e formação profissional. Trata-se de um estudo descritivo, com abordagem qualitativa, e pesquisa bibliográfica em livros e teses que versam o tema. Assim, relacionar teoria e prática oportuniza desenvolvimento de competências e aprendizagem, invertendo a lógica do aprender, estimulando os alunos a se transformarem em sujeitos ativos para pensar e construir sua visão de mundo. Portanto, o ensino do empreendedorismo através de uma metodologia teórico prática, capacita os alunos para empreenderem e atuarem no mercado de trabalho, tornando-se profissionais proativos e criadores de soluções inovadoras.

\section{Palavras chaves: Empreendedorismo. Educação. Gerenciamento.}

\section{Introdução}

A experiência prática incentiva o aluno a pesquisar, buscar informações que o ajudem a realizar melhor as suas tarefas, com isso ele aprende e consegue fixar melhor o conteúdo. Nesse contexto, a criação e gerenciamento de uma miniempresa no ambiente acadêmico, fornece ao educando: conhecimento, inspiração, orientação, encorajamento e motivação para empreender. Além disso, enquanto está gerenciando seu negócio, ele recebe orientações sobre mercado, produtos/serviços, recursos, fornecedores e concorrentes, para planejar o melhor caminho e alcançar os melhores resultados.

Também, oportuniza o contato com o planejamento de uma empresa, elaborando o plano de negócios e traçando estratégias para atingir o alvo projetado. Assim, poderá rever práticas habituais, através de soluções inovadoras, para alcançar vantagem em relação aos seus concorrentes. Desse modo, a competitividade empresarial é impulsionada pela capacidade de aprender, inovar e se adaptar ao ambiente instável do mercado.

Acrescenta-se também, que faz contato com outros empreendedores aprendizes trocando ideias e experiências, descobrindo e desmistificando o conceito de que o empreendedorismo é a última opção para quem está sem emprego, podendo tornar-se a primeira opção para quem deseja trabalhar e ter sucesso profissional, desenvolvendo competências, tanto em relação à visão econômica, quanto em sua interação social.

Nessa perspectiva, mudanças nas metodologias de ensino são necessárias, visando preparar o aluno para lidar com o mercado de trabalho, seja como um funcionário de uma empresa, com inovações e resolução de problemas, seja criando uma empresa e contribuindo para a economia do país. Por isso, a prática empreendedora através da criação e gerenciamento 
de uma miniempresa, representa um método para desenvolvimento de competências e aprendizagem empreendedora, uma vez que promove experiências enriquecedoras e são fontes de aprendizado.

Assim, o aprendizado emerge a partir de metodologias que levem os educandos a relacionar teoria e prática, estimulando-os a pensar, criar e decidir como um sujeito ativo e independente, desenvolvendo competências empreendedoras. Neste sentido, a formação empreendedora se fundamenta nos pressupostos de Politis (2005) apud Cardoso (2017) que descreve o ensino de empreendedorismo pautado em 3 (três) fatores: conhecimento através da prática para identificar oportunidades e gerenciar negócios, experiência acumulada pela vida e finalmente a transformação da experiência em conhecimento.

Nessa lógica, esse estudo tem como objetivo demonstrar a prática de criação e gerenciamento de uma miniempresa, como metodologia de ensino e suas contribuições para o desenvolvimento de características empreendedoras e formação profissional. Como objetivos específicos, destaca-se: analisar a experiência empreendedora na gestão de uma miniempresa e a motivação para empreender; identificar as habilidades e características desenvolvidas no discente durante a prática empreendedora; compreender como a gestão de uma miniempresa contribui com a formação profissional do estudante.

O presente trabalho foi desenvolvido utilizando pesquisas bibliográficas em livros e publicações científicas da área de empreendedorismo e educação empreendedora servindo como base para a análise da prática empreendedora como método de ensino, invertendo a lógica do aprender, estimulando os alunos a se transformarem em sujeitos ativos para pensar e construir sua visão de mundo, seguindo os preceitos de Freire (1975) alicerçados em uma pedagogia crítica, capaz de desafiar o educando a refletir sobre sua realidade social e econômica, enquanto os docentes assumem apenas o papel de mentor, mediador e orientador do conhecimento.

Além disso, espera-se com esse trabalho contribuir para a comunidade acadêmica, mostrando a importância do empreendedorismo no ensino superior para a formação profissional de estudantes das mais variadas áreas, por meio da criação e gerenciamento de uma miniempresa. Desse modo, incentivar o desenvolvimento de características comportamentais, a partir de métodos alternativos de ensino, com objetivo de ampliar habilidades e competências empreendedoras nos educandos, preparando-os para tomar decisões assertivas na gestão de um negócio, contribuindo ainda com desenvolvimento da economia local.

\section{Referencial teórico}

\subsection{Empreendedorismo}

Muitos acreditavam que empreendedor era o indivíduo que tem uma empresa, no entanto, o verdadeiro empreendedor é aquele que tem visão e sabe identificar uma oportunidade e diferenciá-la de uma ideia. Para Chiavenato (2012), empreendedor é a pessoa que cria e/ou melhora a eficácia de um negócio para realizar aproveitar uma oportunidade ou projeto pessoal assumindo riscos e responsabilidades, inovando continuamente. É também um insatisfeito que transforma o seu inconformismo em descobertas e propostas positivas para si e para os outros (DOLABELA, 2008). 
Outro autor que conceitua o empreendedor é Dornelas (2012) quando diz que "representa aquele que faz as coisas acontecerem, se antecipa aos fatos e tem uma visão futura da organização". Eles também são "fornecedores de mercadorias, serviços, informações ou entretenimento, poderosas fontes de energia, que assumem riscos inerentes em uma economia em mudança, transformação e crescimento" (CHIAVENATO, 2012).

Complementa este conceito a visão Schumpeter (1949) apud Chiavenato (2012) quando diz ser "uma pessoa que destrói a ordem econômica existente graças à introdução no mercado de novos produtos/serviços, pela criação de novas formas de gestão ou pela exploração de novos recursos, materiais e tecnologias". Este comportamento é impulsionado pela busca de objetivos, desafios e necessidade de auto realização.

O empreendedor, é uma pessoa corajosa, sonhadora, persuasiva e persistente, que não se deixa abater nas primeiras dificuldades, é capaz de montar um negócio do zero, desde a identificação de uma oportunidade até sua completa implantação, buscando recursos e lutando contra as adversidades que aparecem em seu caminho. Assim, Hisrich (2009) aponta que:

em quase todas as definições de empreendedorismo, há um consenso de que se refere a um tipo de comportamento que abrange: tomar iniciativa, organizar e reorganizar mecanismos sociais e econômicos, a fim de transformar recursos e situações para proveito prático e aceitar o risco ou o fracasso.

Corroboram com este pensamento, Schumpeter (1934) apud Chiavenato (2012), quando advogam que o "empreendedorismo força a destruição criativa nos mercados e indústrias, criando simultaneamente, novos produtos e modelos de negócios". Outro autor que complementa esta ideia é Biagio (2012), ao dizer que empreender "é executar, pôr em prática ou levar adiante um projeto, com a intenção de atingir objetivos e resultados". Portanto, empreendedorismo reflete a prática de criar novos negócios ou revitalizar aqueles já existentes (CHIAVENATO, 2012).

Enfim, empreendedorismo está relacionado à disposição de planejar, capacidade de idealizar, coordenar, dirigir e realizar projetos. No entanto, são características que não precisam estar relacionadas diretamente aos negócios, uma pessoa pode ser empreendedora também como colaborador de uma empresa. Trata-se afinal de pensamento estratégico, otimismo, resiliência, adaptação, capacidade de lidar com a ansiedade e riscos, desejo de mudança, adaptando-se com proatividade.

\subsection{Educação empreendedora}

No Brasil, a pesquisa realizada pela GLOBAL ENTREPRENEURSHIP MONITOR (GEM), coordenada pelo Instituto Brasileiro da Qualidade e Produtividade - IBQP, em parceria com o Serviço Brasileiro de Apoio às Micro e Pequenas Empresas - Sebrae, desde o ano 2000, mostra o país como empreendedor, principalmente os iniciais, posicionado na $6^{\text {a }}$ posição (GEM, 2018). Essas informações têm servido de parâmetro para publicações acadêmicas, formulação de políticas públicas e instituições que acreditam na formação empreendedora.

Nessa perspectiva, o empreendedorismo é ofertado como disciplina por várias Instituições de Ensino Superior (IES) em variados cursos, incentivando a disseminação de uma cultura empreendedora e desenvolvimento de novos negócios. Entretanto, percebe-se que 
mesmo com os avanços, o ensino do empreendedorismo ainda é realizado com métodos tradicionais, que não facilitam a aquisição de habilidades práticas e experiências necessárias a formação de novos empreendedores.

Neste sentido, é necessário criar um ambiente que estimule a prática como método de ensino do empreendedorismo, pois ajudará como afirma Dornelas (2012) na formação de melhores empreendedores, empresários e empresas, contribuindo também com maior geração de riqueza ao país. Esta ação permite ao aluno vivências de gestão, fazendo com que os mesmos ganhem experiência, que poderão ser usadas em diferentes momentos de sua vida profissional.

Nesse âmbito, a educação empreendedora tem a função de desenvolver nos educandos o comportamento empreendedor. E, a partir de uma vivência real, aprender com os teóricos que discutem o tema, com seus pares observando seus erros e acertos, com empreendedores da região analisando as características que impulsionaram o sucesso e principalmente, que enxerguem o professor como um facilitador do saber, uma vez que o aprender fazendo estimula iniciativas que podem desenvolver e aprimorar seu espírito empreendedor.

Estas experiências são vivenciadas ao longo de vida de um educando, com destaque para o papel de suas primeiras práticas de carreira no desenvolvimento do processo empreendedor de reconhecimento e exploração de oportunidades (Politis, 2005 apud Cardoso 2017). Com essa metodologia espera-se estimular os alunos a vontade de empreender, mostrando-lhes os caminhos para a criação de uma nova organização, desenvolvendo características que os farão se destacar entre os demais, com comprometimento, garra, empoderamento e principalmente autoconfiança para tomar decisões.

\subsection{Gestão empreendedora}

A gestão empreendedora tem como parâmetro o emprego de conceitos do empreendedorismo, ações e estratégias utilizando pessoas, estruturas e recursos financeiros na administração de um negócio. Dentre tantos, destaca-se a criatividade, inovação, análise de oportunidades, melhoria contínua, troca de experiências e elaboração de um plano estratégico que o auxiliará a pensar no longo prazo da empresa. Nesse sentido, Chiavenato (2012), escreveu:

por ter criatividade e um alto nível de energia, o empreendedor demonstra imaginação e perseverança, aspectos que, combinados adequadamente, habilitam-no a transformar uma ideia simples em algo que produza resultados concretos e bem sucedidos no mercado.

Portanto, disseminar uma cultura empreendedora envolve a utilização de métodos de aprendizagem que incentivem a prática do empreendedorismo e favoreçam o desenvolvimento de competências relacionadas a: autonomia, planejamento, proatividade, iniciativa, criatividade, relacionamentos construtivos, estabelecimento de metas, liderança, resolução de problemas, busca de informações e recursos, inovação e ética. Assim, a gestão empreendedora será capaz da organização efetiva dos processos, a eficácia na administração dos recursos e principalmente, um ambiente propício à participação e aprendizado.

\section{Metodologia}


O presente artigo foi elaborado com base em pesquisa bibliográfica, a partir livros, teses, dissertações e artigos (Gil, 2014). Esse método foi escolhido em função da necessidade de embasamento teórico para conceituação e comparação entre a literatura e a prática como método de ensino de empreendedorismo. A pesquisa classifica-se como descritiva, pois expõe os aspectos inerentes ao empreendedorismo e as características empreendedoras, acompanhando Gil (2014), quando descreve que este tipo de pesquisa tem como objetivo elencar as características de determinada população ou fenômeno, ou ainda estabelecer relações entre variáveis.

E também é qualitativa, de acordo com Stake (2011), pois os pesquisadores buscam dados que representam experiências pessoais em situações específicas. Ele explica também que o investigador utiliza todos os tipos de dados para clarificar a situação que está ocorrendo, buscando entender e descrever os efeitos causados pela criação e gerenciamento de uma miniempresa, em um ambiente complexo que necessita de liberdade de ação, criatividade e inovação como requisito para o sucesso de seu empreendimento.

\section{A experiência de gestão de uma miniempresa como método para a educação empreendedora}

O projeto de criação e gerenciamento de miniempresas foi implantado no Instituto Federal de Educação do Ceará (IFCE) - Campus Baturité como método de ensino, para disseminar a cultura empreendedora, como explica Braun (2011), "com objetivo de tirar o aluno da sua zona de conforto, proporcionar uma experiência real da prática empreendedora, desde a concepção de uma ideia até a obtenção de resultados". Desse modo, os educandos vivenciam no ambiente acadêmico, a experiência de criar um negócio: analisando o mercado, escolhendo os sócios, buscando recursos financeiros, escolhendo os parceiros, além de planejar, organizar e controlar sua miniempresa.

Além disso, a educação empreendedora aliada a prática encoraja o aluno para abrir seu próprio negócio, também desperta seu comportamento criativo e inovador, habilidade para trabalhar em equipe, contribuindo com sua formação profissional. E, mesmo que no futuro ele não queira empreender, poderá utilizar o aprendizado adquirido para agir de forma empreendedora trabalhando para uma empresa já existente no mercado.

Outro aspecto importante da prática empreendedora no IFCE - Campus Baturité, é a oportunidade do aluno de relacionar teoria e prática, aprendendo através de situações concretas e reais, experimentando situações que favoreçam a análise dos seus erros e acertos, aproveitando a expertise do professor como facilitador para aprender a empreender, trocar experiências com seus colegas, aumentando suas chances de sucesso como empreendedor por oportunidade. Assim, o empreendedor iniciante aumenta sua autoconfiança para planejar seu próprio negócio, assumindo riscos calculados.

Além disso, existem outros fatores que influenciam a decisão de empreender, que também devem ser analisadas, como explicam Fiala e Andreassi (2013), no modelo do processo empreendedor criado por Bygrave (2004), são eles: pessoais, sociais e ambientais. Estes aspectos também inspiram a gênese de uma miniempresa, como pode ser visto na figura 01 , a seguir: 
Figura 01 - Processo empreendedor de uma miniempresa

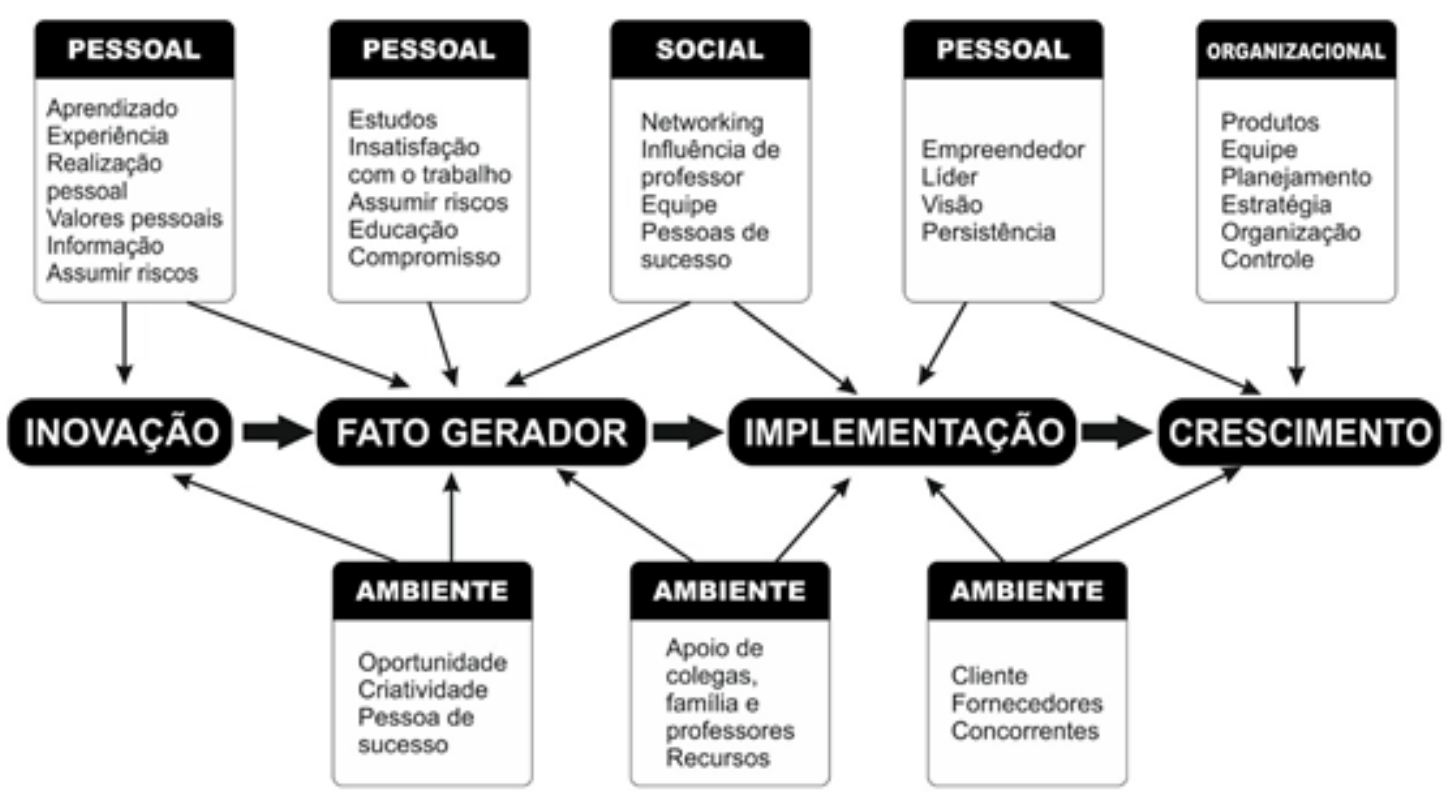

Fonte: Elaborado pelas autoras (2019) adaptado de Bygrave (2004).

Dessa forma, a associação entre teoria e prática e a compreensão dos fatores que influenciam a decisão de empreender, fazem toda a diferença para o desenvolvimento do processo empreendedor, pois será um norte para os melhores métodos para implantação de uma miniempresa, quais pesquisas deverão ser feitas, quais as melhores práticas de gestão, quais processos envolvem sua gênese e gerenciamento e a partir das informações colhidas criar estratégias e tomar decisões assertivas.

Entretanto, uma educação empreendedora necessita de uma proposta pedagógica comprometida com o empreendedorismo e dedicação do corpo docente, para adotar uma metodologia de ensino com instrumentos pedagógicos adequados, inserindo no programa didático de uma disciplina a prática de empreender. Este método poderá despertar nos aprendizes o espírito empreendedor, uma vez que de acordo com Dolabela (2008):

é um potencial de qualquer ser humano e necessita de algumas condições indispensáveis para se materializar e produzir efeitos. Dentre elas estão: o ambiente macro, a democracia, a cooperação e a estrutura de poder em forma de rede, para afloramento do espírito empreendedor, que é um dos componentes do capital humano.

Esta afirmação sugere uma reflexão quanto aos métodos tradicionais de ensino, uma vez que neles os conteúdos são explicados como verdades absolutas, transmitidos em direção única, do docente para os alunos, sem considerar que todos os dias, em situações variadas, os estudantes aprendem com suas experiências. Desse modo, o potencial empreendedor é desperdiçado, pois os aprendizes não conseguem enxergar nesse tipo de educação, as condições essenciais para a abertura e administração de um negócio. 
Em contrapartida, quando o aluno é instigado a realizar uma atividade prática relacionando com conteúdos teóricos, ele terá o ensejo de produzir seu conhecimento através de uma situação em que o próprio está inserido, aprendendo com seus erros e acertos. Nesse processo, o professor desempenha apenas o papel de orientador, prestando esclarecimentos, sanando dúvidas e indicando caminhos para realização da atividade planejada.

Esse processo de orientação empreendedora, na concepção de Lumpkin e Dess (1996) apud Martens e Freitas (2008), refere-se aos métodos, práticas e estilo de tomada de decisão gerencial usados para agir de forma empreendedora. Completando esse pensamento Miller (1983) apud Martens e Freitas (2008), afirmam que em pequenas empresas o empreendedorismo é predominantemente influenciado pelo líder, sua personalidade, sua força e sua informação. Neste sentido, o gerenciamento das miniempresas são afetados pelo comportamento de seus sócios. Além disso, a performance das miniempresas também podem ser instigadas por fatores ambientais e organizacionais que interferem tanto em seu desempenho como na atitude do aprendiz a empreendedor.

Partindo desse pressuposto, os fatores identificados no (quadro 1), a seguir, remetem a necessidade de enfoque sistêmico, visualizando a miniempresa como um todo, bem como sua complexidade. E, a partir desses princípios agregar valor aos seus produtos e serviços, exercendo uma gestão baseada na excelência.

\begin{tabular}{|l|l|}
\hline \multicolumn{2}{|l|}{ Fatores moderadores } \\
\hline Fatores ambientais & Performance organizacional \\
Padrão de qualidade & Boa lucratividade \\
Habilidades humanas & Crescimento de vendas \\
Conhecimento & Satisfação do cliente \\
Desenvolvimento & Retenção de clientes \\
\hline Fatores organizacionais & Orientação empreendedora \\
Produção enxuta & Inovação \\
Recursos & Comprometimento \\
Divisão de tarefas & Proatividade \\
\hline
\end{tabular}

Fonte: Elaborado pelas autoras (2019) adaptado de Lumpkin e Dess (1996)

O gerenciamento da miniempresa, além de proporcionar um ambiente de aprendizado real, também motiva, desperta as habilidades de venda, persuasão, capacidade de comunicação, estimula autonomia e permite ainda, seguir uma educação empreendedora, com foco em inovação. Está prática explora a aprendizagem empreendedora, como um processo real de experiências, com objetivo de exercitar uma metodologia que interliga teoria e prática, pensando de forma crítica e criativa, organizando informações e ideias, tomando decisões.

Enfim, adquirir conhecimentos através da criação e gerenciamento de um mini empreendimento, como mostra os passos no (quadro 2) a seguir. Desse modo, compreender como deve se comunicar com o seu cliente, entender suas necessidades e desejos, para assim, correr riscos calculados e agregar valor a produtos e/ou serviços, seja no modo de preparo do produto, na forma de comercialização ou nas estratégias de vendas. 


\begin{tabular}{|c|c|c|}
\hline \multicolumn{3}{|c|}{ Passos para criação de uma Miniempresa } \\
\hline Passos & Ações & Resultados esperados \\
\hline $\begin{array}{l}\text { 1. Discussão sobre a } \\
\text { metodologia, com } \\
\text { leitura de textos e } \\
\text { debate. }\end{array}$ & $\begin{array}{l}\text { Leitura, resumo e discussão } \\
\text { sobre a importância a } \\
\text { educação empreendedora }\end{array}$ & $\begin{array}{l}\text { Sensibilização e aprendizagem sobre } \\
\text { a Cultura Empreendedora, } \\
\text { Empreendedorismo e } \\
\text { Comportamento Empreendedor. }\end{array}$ \\
\hline $\begin{array}{l}\text { 2. Escolha dos } \\
\text { componentes da } \\
\text { equipe (mínimo } 2 \\
\text { e máximo 3) }\end{array}$ & $\begin{array}{l}\text { Escolha dos sócios da } \\
\text { miniempresa. }\end{array}$ & $\begin{array}{l}\text { Escolha de sócios que tenham perfil } \\
\text { empreendedor complementares, } \\
\text { interessados e comprometidos com os } \\
\text { resultados }\end{array}$ \\
\hline $\begin{array}{l}\text { 3. Pesquisa de } \\
\text { mercado }\end{array}$ & $\begin{array}{l}\text { Elaborar pesquisa de } \\
\text { cliente, fornecedores e } \\
\text { marketing }\end{array}$ & $\begin{array}{l}\text { Conhecer o mercado e o cliente, } \\
\text { analisar oportunidades visualizadas, } \\
\text { definir produto a ser trabalhado, } \\
\text { elaborar estratégias e correr riscos } \\
\text { calculados. }\end{array}$ \\
\hline 4. Escolha do nome & $\begin{array}{l}\text { Escolher o nome que } \\
\text { representará a miniempresa }\end{array}$ & $\begin{array}{l}\text { O nome deverá ser fácil de ser } \\
\text { lembrado, curto, único, claro, deverá } \\
\text { vender a identidade da marca e } \\
\text { conectar a miniempresa ao seu } \\
\text { público alvo }\end{array}$ \\
\hline $\begin{array}{l}\text { 5. Elaboração da } \\
\text { marca }\end{array}$ & $\begin{array}{l}\text { Criar logotipo da } \\
\text { miniempresa }\end{array}$ & $\begin{array}{l}\text { Deve ilustrar claramente o que a } \\
\text { empresa representa e faz }\end{array}$ \\
\hline $\begin{array}{l}\text { 6. Elaboração do } \\
\text { miniplano }\end{array}$ & $\begin{array}{l}\text { Analisar os dados da } \\
\text { pesquisa de mercado para } \\
\text { elaborar o miniplano }\end{array}$ & $\begin{array}{l}\text { Planejar e definir missão, visão, } \\
\text { metas, objetivos público alvo e } \\
\text { fornecedores. }\end{array}$ \\
\hline $\begin{array}{l}\text { 7. Análise da } \\
\text { aceitação da } \\
\text { miniempresa }\end{array}$ & $\begin{array}{l}\text { Implementação da } \\
\text { miniempresa }\end{array}$ & $\begin{array}{l}\text { Colocar a miniempresa em ação, } \\
\text { usando as estratégias definidas. }\end{array}$ \\
\hline 8. Gerenciamento & $\begin{array}{l}\text { Análise do funcionamento, } \\
\text { planejamento, organização, } \\
\text { controle e crescimento da } \\
\text { miniempresa }\end{array}$ & $\begin{array}{l}\text { Aprender com os próprios erros, } \\
\text { despertar a criatividade para a } \\
\text { resolução de problemas. }\end{array}$ \\
\hline
\end{tabular}




\begin{tabular}{|l|l|l|}
\hline 9. Resultados & $\begin{array}{l}\text { Apresentação dos } \\
\text { resultados e dificuldades } \\
\text { vivenciadas na criação e } \\
\text { gerenciamento da } \\
\text { miniempresa }\end{array}$ & $\begin{array}{l}\text { Compartilhar e multiplicar } \\
\text { conhecimentos, através da vivência } \\
\text { com a miniempresa e relato dos } \\
\text { colegas }\end{array}$ \\
\hline
\end{tabular}

Fonte: Elaborado pelas autoras (2019)

Com este método de ensino, Freire (1999) apud Cardoso (2017) defende que as práticas não podem ser dissociadas da teoria, e os conceitos e definições são necessários para uma educação crítica, emancipadora e inovadora. Seguindo esse pensamento, o processo de criação e gerenciamento de uma miniempresa ocorre no período de 6 meses, começando com aula teórica, onde é exposta e discutida a metodologia de ensino, seguido de como será o gerenciamento da miniempresa e o que se espera em termos de resultados. No final do semestre cada equipe deverá compartilhar com seus pares as experiências, dificuldades e aprendizados adquiridos, com a vivência do gerenciamento de suas miniempresas.

Com essa metodologia de ensino é possível proporcionar ao aluno um olhar ampliado sobre si mesmo, sobre os fatores dos ambientes: interno e externo, pois ele aprende administrando do seu próprio negócio, com autonomia na tomada de decisões. Incentiva-o ainda a desenvolver competências empreendedoras, construindo um saber empreendedor capaz de mapear cenários e gerenciar informações para efetividade organizacional, uma vez que são os principais responsáveis pela criação, manutenção, gestão e crescimento de suas miniempresas.

\section{Considerações finais}

Uma empresa para se manter no mercado deve conhecer seu ambiente, pois seu sucesso ou fracasso está ligado à sua capacidade de entender e conhecer o mercado em que atua, sua estrutura, seu know-how, capacidade para atrair e satisfazer os clientes. Desse modo, é necessário que o empresário possua um perfil empreendedor relacionado à identificação de oportunidades, planejamento, correr riscos calculados, gerenciar processos, recursos e pessoas, com o objetivo de alcançar resultados e crescimento de seus negócios.

Entretanto, para compreender o empreendedorismo nesta acepção, é importante analisar como os empreendedores desenvolvem suas competências. Por isso, é fundamental entender como ocorre o processo de aprendizagem empreendedora, uma vez que experiência prévia na criação e gestão de negócios, poderá prover o aprendiz, com informações sobre mercado, clientes, concorrentes, fornecedores, produtos, serviços, processos, recursos e pessoas, transformando suas vivências em conhecimento.

Neste sentido, a criação e gerenciamento de uma miniempresa como método de ensino, para disseminação de uma cultura empreendedora, poderá estimular o protagonismo dos estudantes, por meio das experiências vivenciadas nas diferentes situações práticas, construindo um saber empreendedor, manifestado nas suas competências empreendedoras e nos métodos de gerenciamento dos negócios.

Neste método de aprendizagem, os aprendizes podem desenvolver seu conhecimento, suas habilidades e atitudes para começar novos negócios e gerenciá-los, aproveitando a experiência prática de empreender durante a disciplina de Empreendedorismo, como 
metodologia de ensino, para expandir sua capacidade cognitiva individual e suas relações sociais. Prepará-los para criar desafios e enfrentar obstáculos. Finalmente, orientá-los para planejar, organizar estratégias e tomar decisões, promovendo maiores oportunidades sucesso e crescimento pessoal e profissional.

Aliado ao empreendedorismo destaca-se a intuição, as experiências e a paixão por sua empresa e pelo que faz. Estes elementos também fazem a diferença para o sucesso do negócio, pois através incentivo a cultura empreendedora, os aprendizes desenvolvem características do comportamento empreendedor, libertando sua capacidade para pensar e agir, solucionado os problemas que surgem no gerenciamento de uma miniempresa, desenvolvendo um profissional com atitude, capacitado para gerenciar qualquer tipo de negócio.

\section{Referências}

BIAGIO, Luiz Arnaldo. Empreendedorismo: construindo seu projeto de vida. Barueri, SP: Manole, 2012. ISBN 978-85-204-3325-6.

CARDOSO, Aline Michelle. Educação empreendedora: métodos alternativos de ensino e aprendizagem para formação do empreendedor. Aline Michelle Cardoso. Campo Limpo Paulista, SP: $\quad$ FACCAMP, 2017. Disponível em: http://www.faccamp.br/new/arq/pdf/mestrado/Documentos/producao_discente/AlineMichelle Cardoso. Acesso em 20.10.2018.

CHIAVENATO, Idalberto. Empreendedorismo: dando asas ao espírito empreendedor. 4. ed. Barueri: Manole, 2012. 313 p. ISBN 978852043277-8.

DOLABELA, Fernando. O segredo de Luísa. Rio de Janeiro: Sintaxe, 2008. 299 p. ISBN 9788575423387.

DORNELAS, José Carlos Assis. Empreendedorismo: transformando ideias em negócios. 4. ed. Rio de Janeiro: Elsevier, 2012. 260 p. ISBN 9788535247589.

DORNELAS, José; SPINELLI, Stephen; ADAMS, Robert. Criação de novos negócios: empreendedorismo para o século XXI. Tradução de Cláudia Mello. 2. ed. São Paulo: Elsevier, 2014. 458 p. ISBN 97885335264586.

FIALA, Nathalia; ANDREASSI, Tales. As incubadoras como ambientes de aprendizagem do empreendedorismo. Fundação Getúlio Vargas, Rio de Janeiro, v. 14, P. 759- 783, 2013.

FREIRE, P. Pedagogia do Oprimido. Rio de Janeiro: Paz e Terra, 1975.

GIL, Antonio de. Métodos e técnicas de pesquisa social. 6. ed. São Paulo: Atlas, 2014. 199 p. ISBN 978-8522451425. 
GLOBAL ENTREPRENEURSHIP MONITOR BRASIL, Empreendedorismo no Brasil Relatório $\quad$ Executivo $2018 . \quad$ Disponível em file:///C:/DOCUMENTOS\%20SOCORRO/EDUCA\%C3\%87\%C3\%83O/IFCE/EMPREEND EDORISMO/Pesquisa\%20GEM\%20-

\%20EMPREENDEDORISMO\%20NO\%20BRASIL\%202018.pdf. Acesso em 28 de outubro de 2019.

HISRICH, Robert D.; PETERS, Michael P.; SHEPHERD, Dean A. Empreendedorismo. Tradução de Teresa Cristina Felix de Sousa. 7. ed. Porto Alegre: Bookman, 2009. 662 p. ISBN 9788577803460 .

MARTENS, C. D. P; FREITAS, Henrique. Orientação empreendedora nas organizações e a busca de sua facilitação. Revista Gestão.Org, V. 6, p. 90-108, ABR. 2008.

MINELLO, I. F. et al. Características comportamentais empreendedoras: um estudo com acadêmicos de administração de uma universidade brasileira. Santa Maria: Rev. Adm. UFSM, v. 10, Edição Especial, p. 72-91, AGO. 2017.

STAKE, Robert E. Pesquisa qualitativa: estudando como as coisas funcionam. Porto Alegre: Penso, 2011. 263 p. ISBN 9788563899323. 